\title{
Practical Application of the Newly Introduced Natural Bone Regeneration (NBR) Concept Utilizing Alloplastic Putty
}

\author{
${ }^{1} \mathrm{G}$ Kotsakis, ${ }^{1} \mathrm{~V}$ Chrepa, ${ }^{2} \mathrm{~S}$ Katta \\ ${ }^{1}$ Private Practice, Athens, Greece \\ ${ }^{2}$ Product Manager, NovaBone Products, Alachua, Florida, USA
}

\begin{abstract}
Correspondence: G Kotsakis, Private Practice, 6 Ypsountos Street, Athens, Greece, Phone: +30 6944292065 e-mail: gkotsakis@krompakotsakisdental.gr
\end{abstract}

\begin{abstract}
Background: The most frequent odontogenic cyst is the radicular or periapical cyst. Enucleation is the treatment of choice for radicular cysts that do not interfere with anatomical landmarks. Though large mandibular cysts exhibit spontaneous bone regeneration, the rate of bone in-growth is not adequate for a near-term implant placement. The case presented evaluates bone regeneration of a calcium phosphosilicate putty (NovaBone Dental Putty, NovaBone Products, Alachua, Florida) (NB Putty) when used to restore a large cystic defect in conjunction with platelet rich fibrin (PRF).

Materials and methods: The patient, a 55-year-old patient presented with dull pain and tooth mobility in the mandibular right premolar area. Clinical examination of the area revealed attachment loss of $13 \mathrm{~mm}$ and $10 \mathrm{~mm}$ on the buccal and $11 \mathrm{~mm}$ and $10 \mathrm{~mm}$ on the lingual side of the right canine and first premolar respectively (Fig. 1). Grade 3 mobility was also recorded for the affected teeth. Preoperative Cone Beam CT (СВCT) revealed a large radiolucency in the apical area of the involved tooth indicative of a periapical cyst. The teeth were extracted and the large defect was restored with NB putty and covered with a PRF membrane that was created from patients serum. The area was evaluated at 3,5 , and 7 months postoperatively.

Results: The healing proceeded uneventfully and the ridge width and height remained stabled during the evaluation period. Seven months CBCT showed good bone regeneration in the defect area. The buccal plate was completely regenerated while the crestal plate was still remodeling. The ridge was adequate enough to place a $4.3 \mathrm{~mm} \times 11 \mathrm{~mm}$ implant.

Conclusion: NB Putty in combination with PRF membrane can be recommended to regenerate cystic defects. However larger, longer term controlled studies are further suggested.
\end{abstract}

Keywords: Radicular cyst, Periapical cyst, Bone graft, Platelet rich fibrin, Alloplast.

\section{INTRODUCTION}

The most frequent odontogenic cyst is the radicular or periapical cyst with its prevalence representing 50.2 to $84.5 \%$ of all odontogenic cysts. ${ }^{1-3}$ Radicular cysts can occur at any age, but are most commonly seen in 30 to 50 -yearold patients. ${ }^{4,5}$ They are usually less than $1 \mathrm{~cm}$ in diameter and occur more frequently in the mandible than the maxilla. ${ }^{4,6}$

Enucleation is the treatment of choice for radicular cysts that do not interfere with anatomical landmarks. Though large mandibular cysts exhibit spontaneous bone regeneration, the rate of bone in-growth is not adequate for a near-term implant placement. Within 12 months of the surgical removal of a large mandibular cyst, the reduction of the defect's diameter is $43.5 \%$ and the increase in bone density is only $48.3 \%{ }^{7}$ Moreover, if the diameter of the cyst is larger than $2 \mathrm{~cm}$, the spontaneous healing of the cyst may result in reduced bone density when compared with the surrounding healthy bone. ${ }^{8}$ In cases, where the extraction of the teeth that are involved with a radicular cyst is mandatory, a larger osseous defect is created and the use of a bone graft will significantly enhance the bone regeneration, so as to facilitate an implant placement.

Traditionally, a bone graft and a barrier membrane are employed in bone regeneration procedures. ${ }^{9}$ The types of bone grafts available include autografts, allografts, xenografts or alloplasts. ${ }^{10,11}$

These types of grafts are used alone or in combination, for guided bone regeneration and their success rates vary vastly in the literature. ${ }^{12}$ Even though autografts have proven osteogenic, osteoinductive and osteoconductive effects, they are not so frequently used in implant dentistry because of limited availability of host bone, the need for an additional donor surgical site and patient discomfort issues. Furthermore, there are reports that their use may be associated with significant resorption. ${ }^{13}$

Alloplastic materials on the other hand are readily available in many sizes and shapes, although their chemical consistency differs among manufacturers. Graft substitutes with a putty/paste-like consistency are gaining popularity. Recently, an alloplast putty was approved for clinical dental 
use (NovaBone Dental Putty, Alachua, Florida, USA) (NB Putty). It is premixed putty dispensed in syringes and cartridges. Its unique consistency and delivery system allows the clinician to fill large defects by injecting the putty directly into the defects, eliminating the need for handling the graft substitute. The paste consistency allows uniform surface contact with the bony walls of the defect and eliminates the dilemma of over or under condensation of the graft material.

Membranes are divided into two groups: Resorbable and nonresorbable. Membranes can be fabricated from animal derived collagen, titanium or synthetic materials, such as PLA/PGA. ${ }^{14}$ Recently, platelet-rich fibrin (PRF), mechanically manipulated to form membranes, has been proposed for use in GBR procedures. ${ }^{15} \mathrm{PRF}$, formed from a blood harvest, is an autologous platelet concentrate that encapsulates growth factor cytokines and leukocytes in a fibrin matrix. According to the literature, the use of the PRF membranes may accelerate the integration and remodeling of the grafted biomaterial. ${ }^{15,16}$ PRF membranes have also been proven to be more suitable for in vitro cultivation of periosteal cells for bone tissue engineering compared to commercially available collagen membranes. ${ }^{17}$

In this case report, an alloplastic putty graft (NB Putty), with unique handling characteristics, is combined with a PRF membrane for bone regeneration in a large defect created by the extraction of two periodontally compromised mandibular teeth that were associated with a large radicular cyst.

\section{History}

The patient, a 55-year-old female, non-smoker with no adverse medical history, presented with a dull pain and tooth mobility in the mandibular right premolar area. Clinical examination of the area revealed attachment loss of $13 \mathrm{~mm}$ and $10 \mathrm{~mm}$ on the buccal and $11 \mathrm{~mm}$ and $10 \mathrm{~mm}$ on the lingual side of the right canine and first premolar respectively (Fig. 1). Grade 3 mobility was also recorded for the affected teeth. Preoperative cone beam CT (CBCT) revealed a large radiolucency in the apical area of the involved tooth, as seen

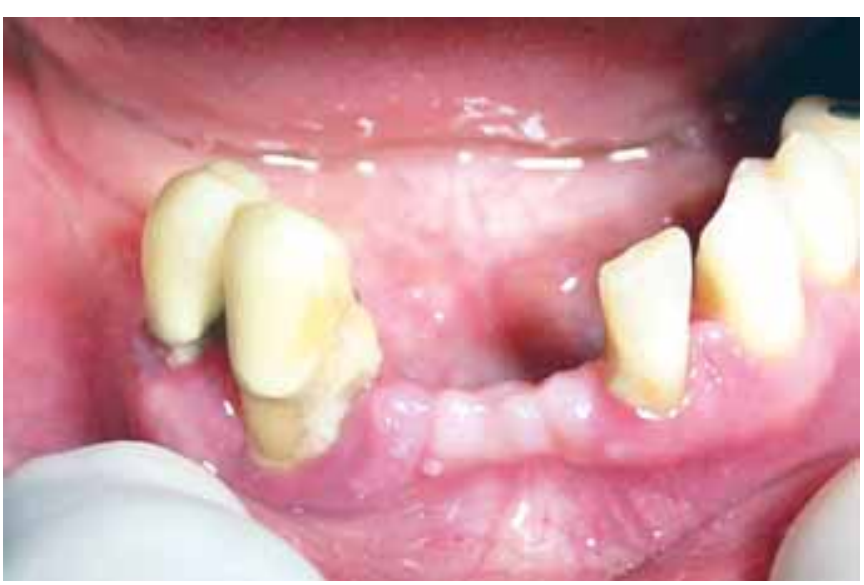

Fig. 1: Clinical view of the compromised teeth nos 27 and 28 in (Fig. 2) (Sections 58-60). Extraction of the teeth, enucleation of the cyst and guided bone regeneration with a bone substitute, prior to implant placement, presented the best prognosis.

\section{Surgical Procedure}

Linear and crevicular incisions were made and both teeth were extracted with forceps. A flap was raised immediately and the cyst was enucleated in toto (Figs 3 and 4). A $23 \times$ $9 \mathrm{~mm}$ defect resulted with no remaining alveolar buccal wall. NB Putty was injected directly into the defect without any prior mixing (Figs 5 and 6).

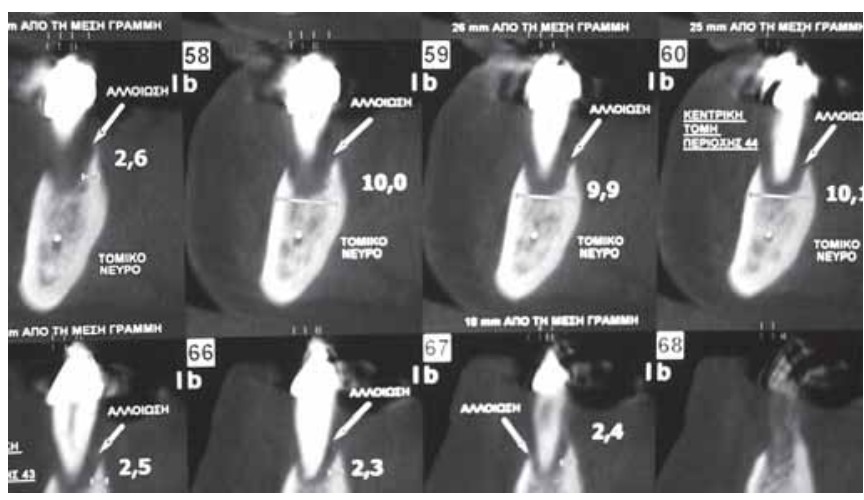

Fig. 2: Preoperative CBCT showing radiolucency in the periapical area. Note that there is no alveolar bone support around the teeth

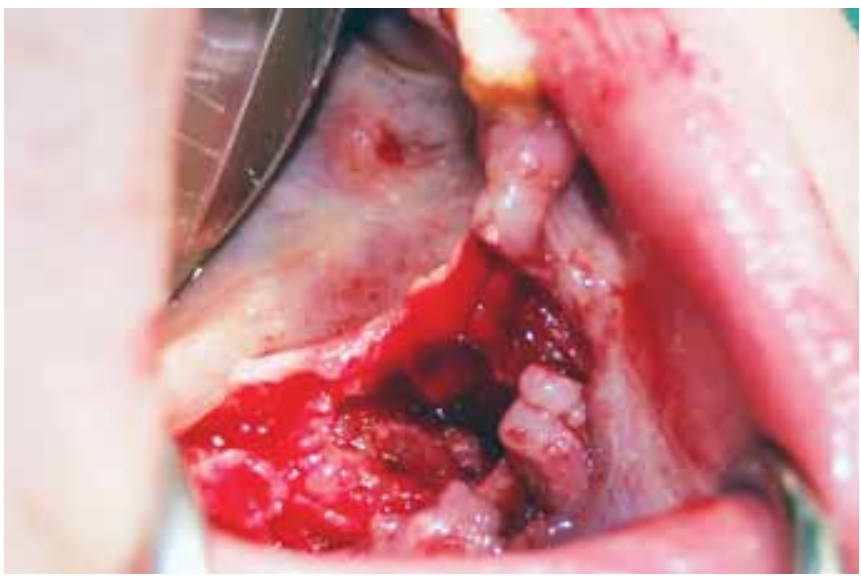

Fig. 3: Clinical view directly after the extraction of the teeth

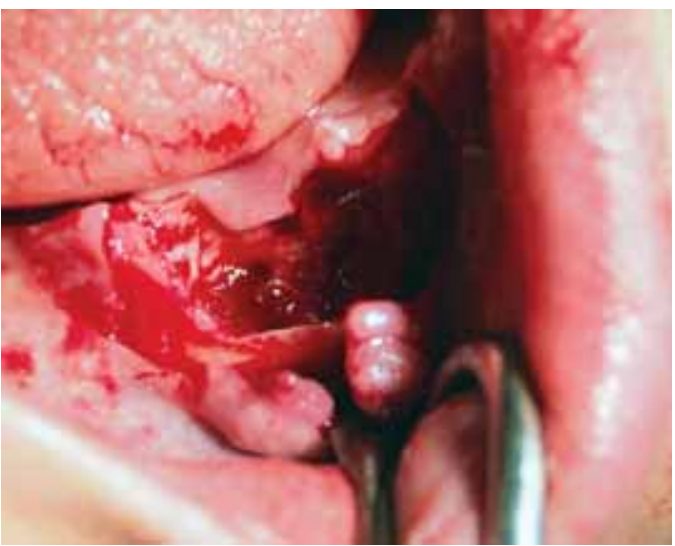

Fig. 4: Osseous defect after the enucleation of the cyst. Note that the buccal plate is completely missing 


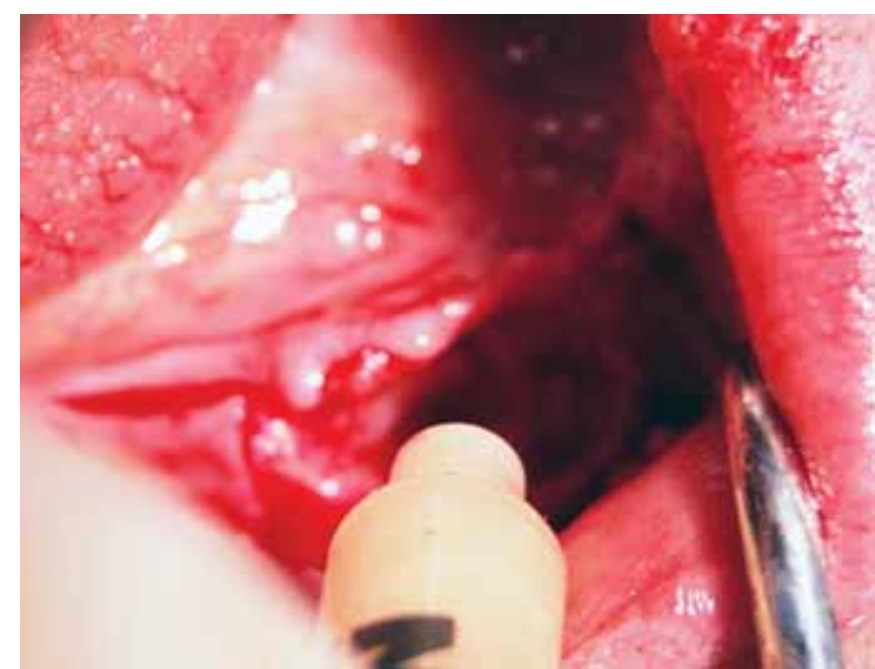

Fig. 5: Placement of NB putty directly from the syringe into the defect

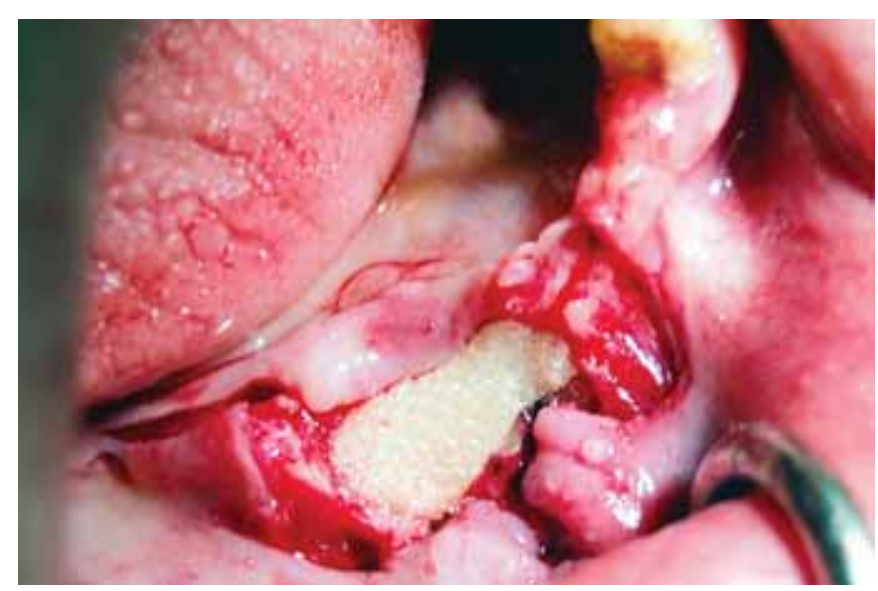

Fig. 6: The defect has been filled with dental putty; the putty's handling characteristics allow it to be easily contoured with the use of a moistened gauze

A PRF membrane, fabricated from the patient's own blood, was used as a barrier. Twenty $\mathrm{ml}$ of the patient's blood were centrifuged in two $10 \mathrm{ml}$ sterile vials at $2900 \mathrm{rpm}$ for 10 minutes and platelet rich fibrin was extracted. Each portion of the PRF was pressured between two gauzes until it formed a membrane, which was used to cover the graft (Figs 7 and 8). Releasing incisions were made using the superficial-layer split-thickness flap technique ${ }^{18}$ and a passive closure was achieved. Two mini dental implants were placed in the area to prevent an interim removable partial denture from impinging on the grafted area.

\section{Results and Follow-up}

The patient was recalled regularly to evaluate healing in the area. The area was clinically evaluated at 3 and 10 days as well as at 3, 5 and 7 months postoperatively. The healing proceeded uneventfully and the ridge height and width remained stable throughout the recall period (Fig. 9).

A 7 months postoperative CBCT (Fig. 10) shows good bone regeneration in the defect area, as seen in sections

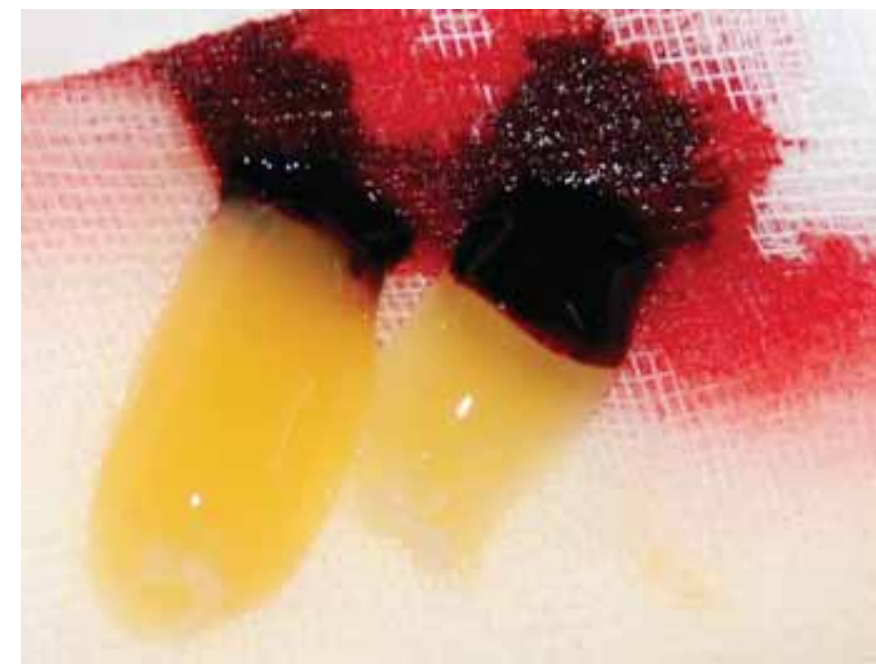

Fig. 7: The PRF clots are placed between two gauzes and steady pressure is applied upon them in order to form PRF membranes

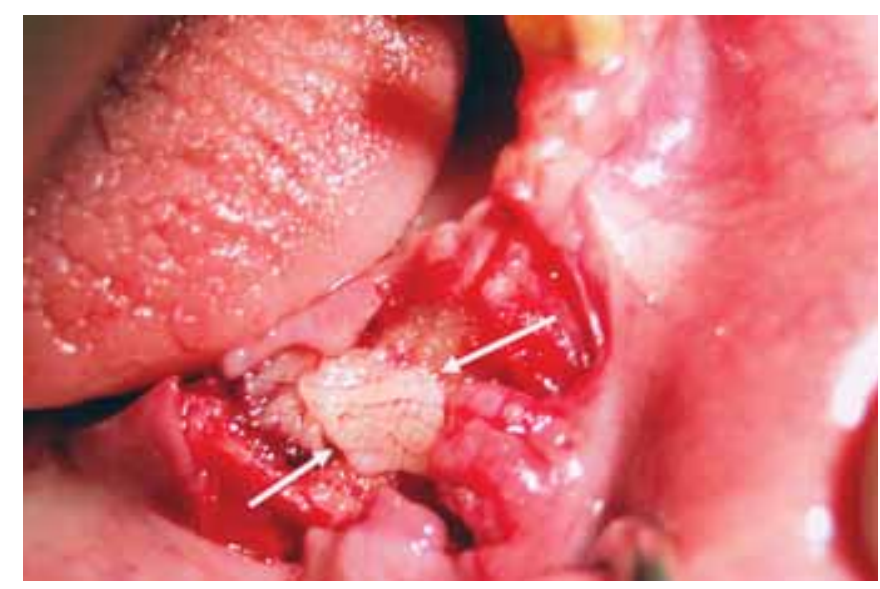

Fig. 8: PRF membranes placement to cover the graft (white arrows)

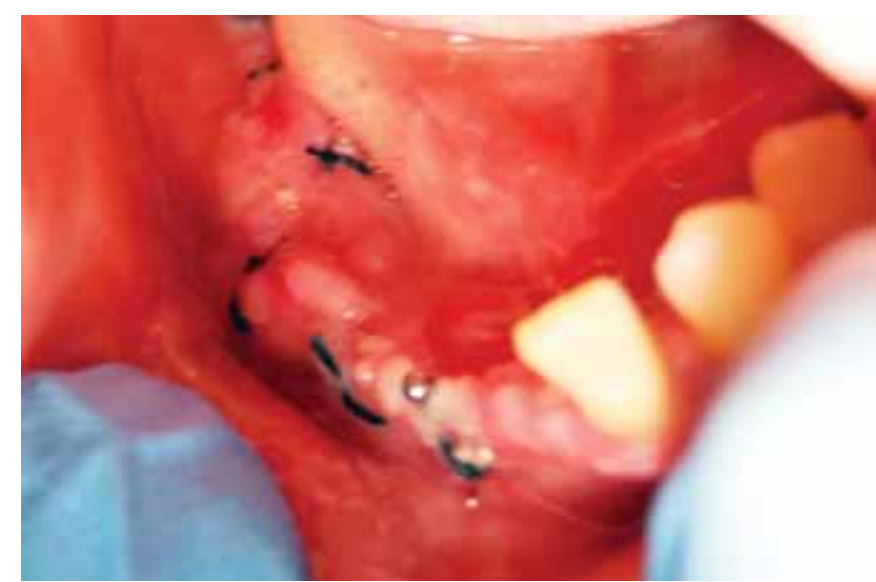

Fig. 9: 3-day postoperative photograph demonstrating excellent wound healing. Note that the epithelium has already covered the incision line

50-52. 8-month postoperative clinical picture reveals a well healed ridge (Fig. 11). Upon re-entry (Fig. 12) shows that, although the crestal plate is still being regenerated, the buccal plate was completely regenerated. Clinically, there was no 


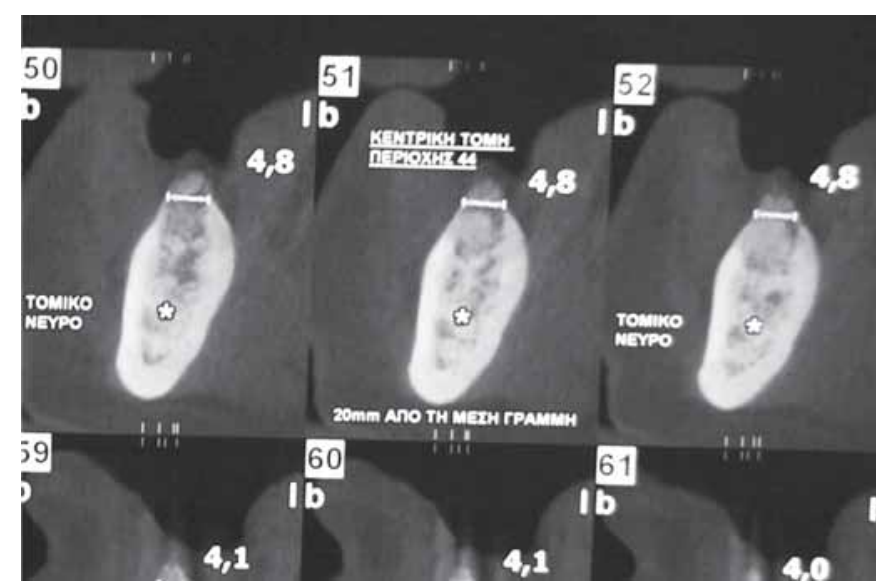

Fig. 10: CBCT showing good bone regeneration

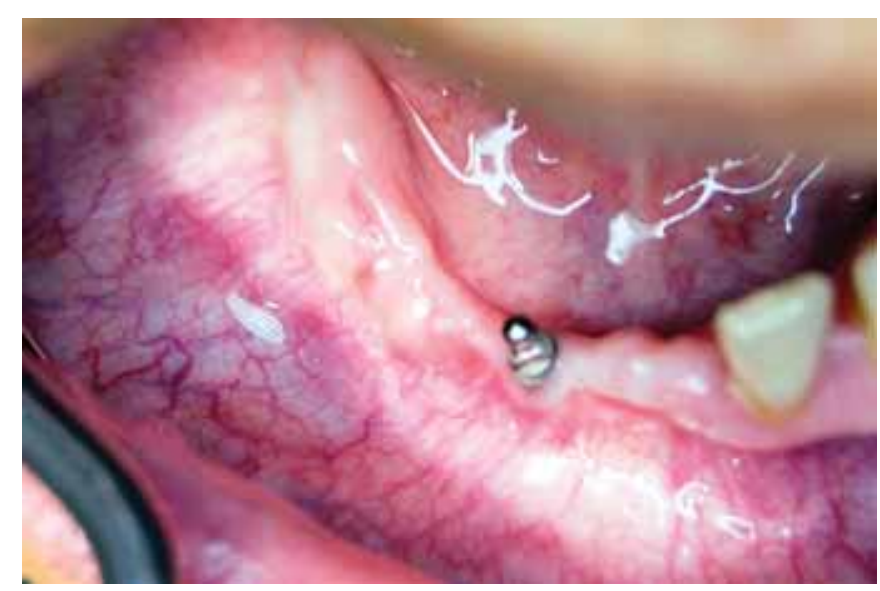

Fig. 11: 8-month postoperative clinical picture

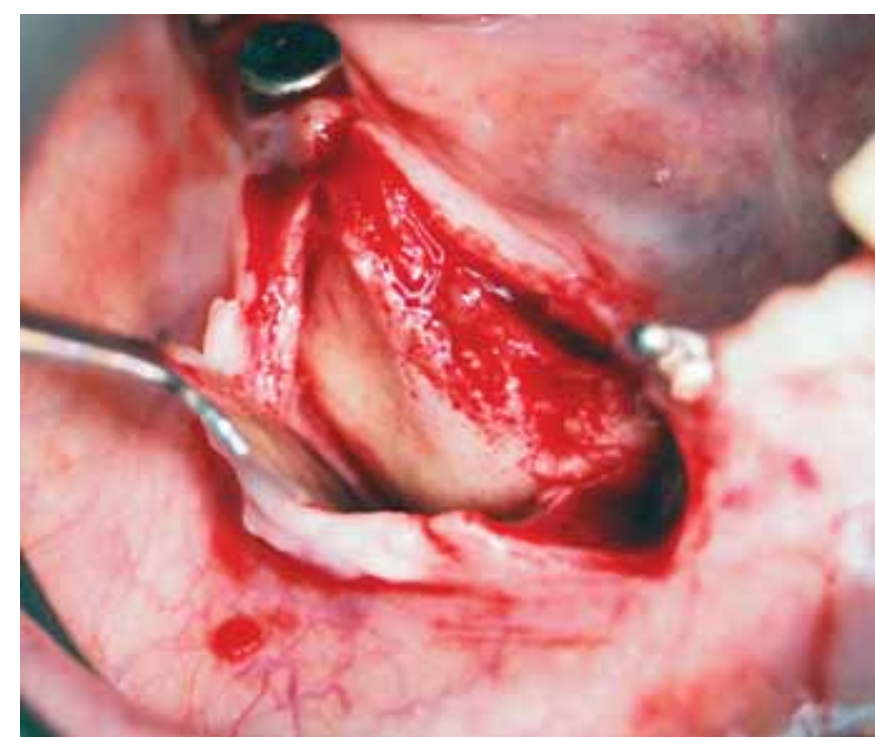

Fig. 12: Clinical picture upon re-entry demonstrates buccal plate regeneration and adequate ridge width for the placement of a standard diameter implant

difference between the grafted area and the native bone, using both visual and handling criteria. The bone dimensions were adequate for the placement of a $4.3 \times 11 \mathrm{~mm}$ implant in the regenerated area, according to the restorative treatment plan, which achieved an initial stability of $45 \mathrm{~N} / \mathrm{cm}^{2}$.

\section{DISCUSSION}

Large cysts that require extraction of multiple teeth, resulting in large defects, pose a challenge to the restoration of the hard and soft tissues required for implant placement. In the present case, both the clinical and CBCT analyses revealed good bone regeneration. Buccal plate regeneration after use of alloplast putty, without a collagen barrier, highlights the bone regeneration potential of NB Putty when used in combination with PRF as a barrier. NB Putty, in conjunction with PRF, satisfactory results in support of the concept of natural bone regeneration that resulted in excellent soft and hard tissue healing. Being synthetic, NB Putty also eliminated the need for an additional surgical site. NB Putty is dispensed premixed and hence eliminated the need for any preparation prior to placement. The material was cohesive, providing adequate graft retention in the defect even during irrigation and suction. It is possible that the performance characteristics seen with the putty are a result of multiple physical and chemical interactions termed osteostimulation. ${ }^{19,20}$ This unique phenomenon occurs in calcium phosphosilicate-based synthetic graft substitutes and has been shown to be superior to conventional osteoconduction.

As far as PRF is concerned, its use has not been extensively researched since its introduction in $2000 .{ }^{21}$ The advantage that PRF yields over earlier autologous growth factor concentrates such as platelet-rich plasma (PRP) is that the platelet derived growth factors are trapped in a dense fibrin matrix and gradually released for a period of at least 7 days. ${ }^{22}$ Moreover, the ease of fabrication of a PRF membrane makes it convenient for use in everyday dental practice. The term natural bone regeneration (NBR) has been recently introduced to describe the novel therapeutic principle that has been available for use to the dental community, utilizing the regenerative potential of PRF in traditional GBR procedures, as it was done successfully in this case report. ${ }^{23}$

\section{CONCLUSION}

The results suggest that natural bone regeneration (NBR), utilizing bioactive calcium phosphosilicate putty in conjunction with platelet-rich-fibrin membranes, may be a reliable choice for osseous regeneration in cases of ridge preservation and implant related surgeries. Large scale controlled trials are required to confirm this result in the future.

\section{REFERENCES}

1. Jones AV, Craig GT, Franklin CD. Range and demographics of odontogenic cysts diagnosed in a UK population over a 30-year period. J Oral Pathol Med 2006;35(8):500-07. 
2. Tortorici S, Amodio E, Massenti MF, Buzzanca ML, Burruano F, Vitale F. Prevalence and distribution of odontogenic cysts in Sicily: 1986-2005. J Oral Sci 2008;50(1):15-18.

3. Nuñez-Urrutia S, Figueiredo R, Gay-Escoda C. Retrospective clinicopathological study of 418 odontogenic cysts. Med Oral Patol Oral Cir Bucal 2010;15(5):e767-73.

4. Weber AL. Imaging of cysts and odontogenic tumors of the jaw. Radiol Clin North Am 1993;31:101-20.

5. Becconsall-Ryan K, Tong D, Love RM. Radiolucent inflammatory jaw lesions: A twenty-year analysis. Int Endod J 2010;43(10):859-65.

6. Avelar RL, Antunes AA, Carvalho RW, Bezerra PG, Oliveira Neto PJ, Andrade ES. Odontogenic cysts: A clinicopathological study of 507 cases. J Oral Sci 2009;51(4):581-86.

7. Chiapasco M, Rossi A, Motta JJ, Crescentini M. Spontaneous bone regeneration after enucleation of large mandibular cysts: A radiographic computed analysis of 27 consecutive cases. J Oral Maxillofac Surg 2000;58(9):942-48.

8. Ihan Hren N, Miljavec M. Spontaneous bone healing of the large bone defects in the mandible. Int J Oral Maxillofac Surg 2008; 37(12):1111-16.

9. Buser D, Dula K, Hess D, Hirt HP, Belser UC. Localized ridge augmentation with autografts and barrier membranes. Periodontol 2000. 1999;19:151-63 (Review).

10. Reynolds MA, Aichelmann-Reidy ME, Branch-Mays GL, Gunsolley JC. The efficacy of bone replacement grafts in the treatment of periodontal osseous defects. A systematic review. Ann Periodontol 2003;8(1):227-65.

11. Browaeys H, Bouvry P, De Bruyn H. A literature review on biomaterials in sinus augmentation procedures. Clin Implant Dent Relat Res 2007;9(3):166-77.

12. Lupovici. Verified osteoinductive allograft putty for dental implant regeneration: Preliminary findings of three clinical applications. JIACD 2011:33-41.

13. Proussaefs P, Lozada J. The use of intraorally harvested autogenous block grafts for vertical alveolar ridge augmentation: A human study. T J Periodon Restor Dent 2005;25(4):351-63.

14. Geurs NC, Korostoff JM, Vassilopoulos PJ, Kang TH, Jeffcoat M, Kellar R, Reddy MS. Clinical and histologic assessment of lateral alveolar ridge augmentation using a synthetic long-term bioabsorbable membrane and an allograft. J Periodontol 2008;79(7):1133-40.
15. Simonpieri A, Del Corso M, Sammartino G, Dohan Ehrenfest DM. The relevance of Choukroun's platelet-rich fibrin and metronidazole during complex maxillary rehabilitations using bone allograft. Part II: Implant surgery, prosthodontics, and survival. Implant Dent 2009;18(3):220-29.

16. Choukroun J, Diss A, Simonpieri A, Girard MO, Schoeffler C, Dohan SL, et al. Platelet-rich fibrin (PRF): A second-generation platelet concentrate (Part IV): Clinical effects on tissue healing. Oral Surg Oral Med Oral Pathol Oral Radiol Endod 2006;101(3):e56-60.

17. Gassling V, Douglas T, Warnke PH, Açil Y, Wiltfang J, Becker ST. Platelet-rich fibrin membranes as scaffolds for periosteal tissue engineering. Clin Oral Implants Res 2010;21(5):543-49.

18. Greenwell H, Vance G, Munninger B, Johnston H. Superficiallayer split-thickness flap for maximal flap release and coronal positioning: A surgical technique. Int J Periodontics Restorative Dent 2004;24(6):521-27.

19. Loty C, Sautier JM, Tan MT, Oboeuf M, Jallot E, Boulekbache H, Greenspan D, Forest N. Bioactive glass stimulates in vitro osteoblast differentiation and creates a favorable template for bone tissue formation. J Bone Min Res 2001;16(2):231-39.

20. Xynos ID, Edgar AJ, Buttery LD, Hench LL, Polak JM. Ionic products of bioactive glass dissolution increase proliferation of human osteoblasts and induce insulin-like growth factor II mRNA expression and protein synthesis. Biochem Biophys Res Commun 2000;276:461-65.

21. Choukroun J, Adda F, Schoeffler C, Vervelle A. Une opportunite' en paro-implantologie: Le PRF. Implantodontie 2000;42:55-62. French.

22. Dohan Ehrenfest DM, de Peppo GM, Doglioli P, Sammartino G. Slow release of growth factors and thrombospondin-1 in Choukroun's platelet-rich fibrin (PRF): A gold standard to achieve for all surgical platelet concentrates technologies. Growth Factors 2009;27(1):63-69.

23. Del Corso M, Vervelle A, Simonpieri A, Jimbo R, Inchingolo F, Sammartino G, Dohan Ehrenfest DM. Current knowledge and perspectives for the use of platelet-rich plasma (PRP) and platelet-rich fibrin (PRF) in oral and maxillofacial surgery. Part 1: Periodontal and dentoalveolar surgery. Curr Pharm Biotechnol 2011. 